\title{
Peran Mediasi Human Capital dan Kinerja Individu dalam Hubungan Praktek MSDM dengan Kinerja Organisasi
}

\author{
Jonner Simarmata \\ Manajemen Fakultas Ekonomi Universitas Batanghari \\ Correspondence email: jonnerunbari@gmail.com
}

\begin{abstract}
This research aims to investigate the role of HC mediation and individual performance in the relationship of MSDM practice with organizational performance in the context of IMK. To achieve this goal, a set of questionnaires was distributed to 300 respondents. They consist of 40 entrepreneurs and 260 craftsmen selected with multi-stage random sampling techniques. The collected data is analyzed by the SEM-PLS method. Data analysis results in that (1) MSDM practices have a positive and significant effect on HC, individual performance, and organizational performance, (2) HC and individual performance mediate the relationship of MSDM practice with organizational performance. The findings of this study have implications for the theory that the relationship of MSDM practice with organizational performance is increasingly clarified. This finding suggests that IMK actors, especially those engaged in the Jambi batik industry, to further streamline HC development and improve individual performance through more effective MSDM practices to achieve more effective organizational goals.
\end{abstract}

Keywords: MSDM practice, Human Capital, individual performance, organizational performance, IMK, Batik Jambi

\section{Pendahuluan}

Industri Menengah Kecil (IMK) berkontribusi terhadap penyerapan tenaga kerja dan Pendapatan Domestik Regional Bruto (PDRB). Di Provinsi Jambi, IMK berkontribusi sangat besar terhadap PDRB dan penyediaan lapangan kerja. Dengan kata lain, IMK merupakan salah satu sektor ekonomi yang sangat signifikan di Provinsi Jambi (BPS Provinsi Jambi, 2020a, 2020b, 2021). Industri batik merupakan salah satu IMK di Provinsi Jambi. Industri batik Jambi (IBJ) memiliki potensi pasar yang sangat besar. Hal ini disebabkan beberapa alasan. Pertama, batik Jambi mengandung nilai budaya sehingga masyarakat memiliki kebanggaan tersediri terhadap produk kreatif ini. Kedua, batik Jambi memiliki motif yang unik dengan warna yang khas Jambi yang dapat mencuri perhatian calon pembeli. Ketiga, kesadaran masyarakat terhadap produk batik termasik batik Jambi semakin meningkat sejak UNESCO (2008) memberi pengakuan batik sebagai warisan budaya Indonesia. Keempat, pasar lokal, nasional, bahkan internasional masih terbuka lebar. Dengan kata lain, batik Jambi menjanjikan pasar yang sangat luar biasa (Octavia \& Sriayudha, 2017; Siregar et al., 2020).

Namun demikian, kinerja organisasi pada IBJ tidak begitu menggembirakan. Hal ini terlihat dari beberapa aspek. Pertama, petumbuhan aset pada IBJ tidak mengalami progress yang signifikan. Data dari Dinas Perindustrian Provinsi Jambi tahun 2020 menunjukkan sebagian besar (68\%) usaha batik Jambi termasuk dalam kategori mikro dengan tenaga kerja berjumlah 1-4 orang. Sementara yang tergolong industri kecil hanya $19 \%$ dan yang tergolong industri menengah hanya 5\%, bahkan yang tergolong industri besar tidak ada atau 0\%. Data ini menunjukkan bahwa pertumbuhan aset pada usaha batik Jambi sangat rendah. Kedua, penyerapan tenaga kerja pada IBJ juga cukup rendah. Berdasarkan data dari Dinas Perindustrian Provinsi Jambi pada tahun 2020 diketahui bahwa jumlah tenaga kerja yang terserap pada IBJ hanya 1206 orang atau hanya 0,05\% dari total angkatan kerja Provinsi Jambi pada tahun 2020. Fenomena di atas mengindikasikan bahwa IBJ perlu mendapat perhatian yang serius agar sektor ini dapat menjadi sektor ekonomi penting di Provinsi Jambi. Perhatian tersebut mencakup perbaikan kinerja organisasi atau kinerja bisnis. Kinerja organisasi merupakan gambaran penting terhadap keberhasilan perusahaan terutama bila kinerja tersebut mencakup kinerja finansial dan kinerja non-finansial (Al-Tit, 2017; Daft, 2000; Kaplan \& Norton, 1992b).

Salah satu faktor yang dapat mempengaruhi kinerja organisasi adalah praktek MSDM. Praktek MSDM adalah kebijakan dan aktivitas manajerial yang membantu karyawan berkontribusi dengan baik terhadap perusahaan. Gamage (2014) melaporkan bahwa perusahaan yang mengimplementasikan MSDM dengan baik berpotensi memiliki kinerja yang lebih baik dibandingkan dengan perusahaan yang tidak melakukan MSDM secara efektif. Akan tetapi, hingga saat ini, bagaimana praktek MSDM mempengaruhi kinerja organisasi masih menyisakan perdebatan. Lebih lanjut, terdapat ketidakkonsistenan hasil-hasil penelitian. Beberapa penelitian menyebutkan bahwa praktek MSDM berkorelasi positif dengan kinerja organisasi. Sebaliknya, beberapa penelitian lain menyimpulkan pengaruh praktek MSDM terhadap kinerja organisasi adalah tidak signifikan (Armstrong \& Taylor, 2014; Sabiu et al., 2019). Dalam hal terdapat ketidakkonsistenan hubungan antara dua variabel atau lebih, peneliti dianjurkan untuk mengambil langkah pendekatan mediasi. Anjuran ini menimbulkan pertanyaan. Variabel apakah yang tepat digunakan untuk memediasi hubungan praktek MSDM dengan kinerja organisasi. Untuk menjawab pertanyaan ini, prinsip Barron \& Kenny dapat digunakan. Menurut Baron \& Kenny (1986), sebuah konstruk dapat menjadi sebuah mediator bila konstruk tersebut 
memiliki hubungan dengan variabel independen dan variabel dependen, dan variabel independen tersebut juga memiliki keterkaitan dengan variabel depeneden.

Berdasarkan prinsip ini, human capital (HC) dan kinerja individu (KI) diyakini memiliki potensi yang besar untuk menjadi mendiator antara praktek MSDM dengan kinerja organisasi. Hal ini terlihat dari definisi praktek MSDM. Menurut Guest (2011), praktek MSDM adalah kebijakan yang mendorong karyawan untuk bekerja lebih baik yang kemudian mempengaruhi kinerja organisasi. Hal ini juga diperkuat pendapat Armstrong (2012) yang mengatakan bahwa praktek MSDM tidak langsung mempengaruhi kinerja organisasi. Akan tetapi, praktek MSDM terlebih dahulu mempengaruhi Kinerja Individu, baru kemudian mempengaruhi kinerja organisasi. Berdasarkan uraian $\mathrm{d}$ atas maka tujuan utama dari penelitian ini adalah untuk mengintesvigasi apakah $\mathrm{HC}$ dan KI dapat memediasi hubungan praktek MSDM dengan kinerja organisasi.

\section{Kinerja Organisasi}

Menurut Daft (2000), kinerja adalah kemampuan untuk mencapai tujuan dengan menggunakan sumber daya secara efektif dan efisien. Menurut Kaplan \& Norton (1992), kinerja organisasi adalah seperangkat indikator keuangan dan non keuangan yang dapat mengukur tingkat pencapaian tujuan organisasi. Pentingnya kinerja organisasi mendorong para ahli untuk membuat konsep pengukuran. Secara tradisional, pengukuran kinerja organisasi didasarkan pada perspektif keuangan semata. Namun, para ahli mengkritik kriteria tunggal ini karena tidak memberikan gambaran yang komprehensif (Keegan et al., 1989). Idealnya, pengukuran kinerja organisasi yang komprehensif adalah pengukuran yang melibatkan aspek finansial dan non finansial. Hal ini sejalan dengan tujuan organisasi. Pada dasarnya, tujuan organisasi adalah untuk menciptakan nilai bagi para pemangku kepentingan. Menanggapi kritik ini, Kaplan \& Norton (1992) mengusulkan keseimbangan antara model keuangan dan nonkeuangan yang disebut Model BSC (Balanced Scorecard). Model BSC dipandang sebagai model pengukuran yang komprehensif karena terdiri dari empat perspektif, yaitu perspektif keuangan, perspektif pelanggan, perspektif proses internal, dan perspektif pertumbuhan.

\section{Pengaruh Praktek MSDM terhadap Kinerja Organisasi}

Manajemen sumber daya manusia (MSDM) didefinisikan sebagai proses mendapatkan, mengembangkan, dan memelihara karyawan (Armstrong \& Taylor, 2014). Dengan demikian, praktek MSDM didefinisikan sebagai kebijakan dan kegiatan manajerial yang bertujuan untuk meningkatkan kontribusi produktif karyawan kepada organisasi Sabiu et al. (2019) berpendapat bahwa MSDM adalah kunci pengembangan organisasi dan karyawan. Praktek MSDM bertujuan untuk meningkatkan kontribusi karyawan terhadap kinerja perusahaan. Hal ini sejalan dengan Resource-Based View (RBV), yang menyatakan bahwa SDM dapat berkontribusi pada kemampuan bersaing perusahaan jika SDM dikelola secara efektif (Barney \& Arikan, 2008). Dengan kata lain, jika praktek MSDM berjalan efektif, maka praktek MSDM akan meningkatkan kinerja organisasi. Berbagai studi empiris membuktikan hubungan antara praktek MSDM dan kinerja organisasi. Semakin efektif MSDM, semakin tinggi kinerja organisasi. Sebaliknya, semakin tidak efektif MSDM maka kinerja organisasi semakin rendah. Huselid (1995) mengungkapkan bahwa praktek MSDM berkorelasi positif dan signifikan dengan produktivitas karyawan dan kinerja keuangan. Selain itu, Bryson \& Forth (2018) mengungkapkan bahwa UKM yang menerapkan manajemen formal berpotensi memiliki kinerja yang lebih tinggi dibandingkan dengan UKM yang tidak menerapkan manajemen formal. Lebih lanjut, Mangai (2011) menemukan bahwa praktek MSDM dalam bentuk rekrutmen, kompensasi, pelatihan, dan penilaian merupakan faktor penting dalam mencapai keberhasilan UKM. Sejalan dengan ini, Banerjee (2017) menemukan korelasi positif dan signifikan antara praktek MSDM dan kinerja organisasi.

\section{Pengaruh Praktek MSDM terhadap Kinerja Organisasi melalui Human Capital}

Human Capital (HC) merupakan aset tidak berwujud berupa pengetahuan, keterampilan, motivasi, dan fleksibilitas yang melekat pada karyawan. $H C$ terkait dengan praktek MSDM. $H C$ adalah hasil akumulasi dari praktek MSDM. Dengan kata lain, praktek MSDM merupakan investasi dalam meningkatkan sumber daya manusia. $H C$ juga memiliki hubungan dengan kinerja organisasi. Perusahaan yang memiliki $H C$ yang efektif cenderung memiliki kinerja organisasi yang tinggi. Dengan kata lain, $H C$ dapat mempengaruhi kinerja organisasi (Obeidat et al., 2017; Tovstiga \& Tulugurova, 2007; ul Rehman et al., 2015). Penelitian menunjukkan bahwa variasi dalam kinerja organisasi dapat dijelaskan oleh $H C$. Semakin tinggi kualitas $H C$, semakin tinggi kinerja organisasi. Sebaliknya, semakin rendah kualitas $H C$, semakin rendah kinerja organisasi. Premis ini juga berlaku untuk organisasi kecil. Misalnya, Yang \& Lin (2009) menemukan bahwa $H C$ memiliki pengaruh yang signifikan terhadap kinerja organisasi. Becker (1964) dan Schultz (1961) berpendapat bahwa $H C$ adalah pengetahuan, keterampilan, dan kemampuan yang dimiliki individu. $H C$ adalah kumpulan kompetensi, pengetahuan, eksperimen, pengalaman, sikap, komitmen, dan kebijaksanaan yang dimiliki individu dalam organisasi. HC terdiri dari kemampuan, perilaku, usaha, dan waktu. Menurut Tovstiga \& Tulugurova (2007), model HC terdiri dari kompetensi, sikap, dan kelincahan intelektual. Kompetensi merupakan 
kombinasi dari pengetahuan, keterampilan, dan pengalaman. Sikap meliputi motivasi, perilaku, dan pola pikir. Sedangkan kelincahan intelektual terdiri dari keinovatifan, kreativitas, fleksibilitas, dan kemampuan beradaptasi.

\section{Pengaruh Praktek MSDM terhadap Kinerja Organisasi melalui Kinerja Individu}

Kinerja karyawan didefinisikan sebagai kontribusi karyawan terhadap organisasi. Kontribusi ini didukung oleh atribut pegawai seperti kompetensi kerja, motivasi kerja, dan sikap kerja yang dimiliki pegawai dalam melaksanakan tugas yang diberikan. Atribut-atribut ini adalah hasil dari praktek MSDM (Armstrong \& Taylor, 2014; Snell \& Dean, 1992). Demikian pula, Kinerja Individu didefinisikan sebagai perilaku yang ditunjukkan oleh karyawan dalam melakukan pekerjaannya. Dengan definisi ini, atribut karyawan yang biasa digunakan untuk mengukur kinerja adalah kompetensi dan motivasi. Kedua elemen ini diyakini sebagai prediktor penting dari Kinerja Individu. Semakin tinggi kompetensi dan motivasi pegawai, maka semakin tinggi pula kinerjanya. Sebaliknya, semakin rendah kompetensi dan motivasi maka semakin rendah pula kinerja pegawai (Armstrong, 2012). Dalam penelitian ini, kinerja individu dilihat dari tiga dimensi, yaitu: (1) kinerja tugas, (2) kinerja kontekstual, (3) kinerja adaptif. Hal ini sejalan dengan model yang dikemukakan oleh (Allworth \& Hesketh, 1999). Menurut Colquitt et al. (2015), kinerja tugas adalah semua perilaku karyawan yang berhubungan langsung dengan transformasi sumber daya organisasi menjadi produk yang dihasilkan perusahaan.

Borman \& Motowidlo (1993) mengidentifikasi lima kategori kinerja kontekstual. Kategori tersebut adalah (a) sukarela untuk melakukan aktivitas tugas yang bukan merupakan bagian formal dari pekerjaan; (b) bertahan dengan antusiasme ekstra bila diperlukan untuk menyelesaikan aktivitas tugas mandiri; (c) membantu dan bekerja sama dengan orang lain; (d) mengikuti aturan dan prosedur organisasi meskipun secara pribadi tidak nyaman; dan (e) mendukung pencapaian tujuan organisasi. Kinerja adaptif adalah kemampuan karyawan untuk beradaptasi dengan lingkungan. Individu dapat membuat perubahan yang signifikan. Kemampuan beradaptasi sangat penting, mengingat perubahan lingkungan yang mempengaruhi efektivitas suatu organisasi dalam mempertahankan keberadaannya (Allworth \& Hesketh, 1999). Demikian pula, Armstrong (2012) berpendapat bahwa praktek MSDM pertama-tama mempengaruhi kinerja individu, kemudian pada akhirnya kinerja organisasi. MSDM adalah manajemen strategis yang menekankan pada perolehan, pengorganisasian, dan motivasi sumber daya manusia. Menurut Armstrong (1999), MSDM adalah operasi manajemen SDM sehari-hari. Praktek MSDM adalah kebijakan dan kegiatan yang ditujukan untuk mengembangkan potensi sumber daya manusia. Praktek MSDM merupakan kegiatan investasi dalam SDM (Snell \& Dean, 1992). Dalam organisasi kecil, peran mediasi kinerja individu juga telah terbukti dalam hubungan antara praktek MSDM dan kinerja organisasi. Banerjee (2017), berpendapat bahwa kinerja individu, yang disebutnya hasil karyawan, berpengaruh positif terhadap kinerja bisnis. Oleh karena itu, dapat diasumsikan bahwa kinerja pegawai dapat memediasi hubungan antara praktek MSDM dengan kinerja organisasi pada industri batik di Provinsi Jambi.

\section{Metode}

Penelitian ini merupakan penelitian survei dengan desain kausal dan pendekatan kuantitatif. Menurut Babbie (2014), penelitian survei bertujuan untuk menggambarkan karakteristik populasi melalui data sampel, menjelaskan hubungan antar variabel yang diteliti, dan memberikan arahan untuk penelitian selanjutnya berdasarkan bukti empiris yang ditemukan. Pendekatan kuantitatif menekankan pada penggunaan data kuantitatif dengan prosedur analisis statistik tertentu. Populasi penelitian ini adalah pengusaha dan pengrajin batik Jambi. Berdasarkan data Dinas Perindustrian dan Perdagangan Provinsi Jambi, saat ini terdapat 84 unit usaha batik Jambi yang tergolong usaha kecil menengah dengan jumlah pengrajin 885 orang. Dengan demikian, populasi keseluruhan adalah 969 orang. Metode Slovin digunakan untuk menentukan jumlah sampel. Dengan metode ini diketahui jumlah sampel minimal 285 orang yang terdiri dari 25 pengusaha dan 260 pengrajin.

Instrumen yang digunakan untuk mengumpulkan data primer adalah seperangkat kuesioner yang disusun secara terstruktur berdasarkan operasionalisasi variabel. Secara keseluruhan, ada 65 item pertanyaan untuk mengukur keempat variabel. Praktek MSDM diukur dengan 20 item yang terdiri dari 5 item untuk rekrutmen \& seleksi diadaptasi dari Khan \& Khan (2012), 5 item untuk pelatihan \& pengembangan, diadaptasi dari Khan \& Khan (2012), 5 item untuk kompensasi, diadaptasi dari Khan \& Khan (2012), dan 5 item penilaian kinerja yang diadaptasi dari Gamage \& Sadoi (2008). HC diukur dengan 9 item yang terdiri dari 3 item untuk kompetensi, diadaptasi dari Tovstiga \& Tulugurova (2007), 3 item untuk sikap, diadaptasi dari Tovstiga \& Tulugurova (2007), dan 3 item untuk agilitas intelektual, diadaptasi dari Tovstiga \& Tulugurova (2007). Kinerja Individu diukur dengan 16 item yang terdiri dari 5 item untuk kinerja tugas, diadaptasi dari Koopmans et al. (2011), 6 item untuk kinerja kontekstual, diadaptasi dari Koopmans et al. (2011), dan 5 item untuk kinerja adaptif yang diadaptasi dari Pulakos et al. (2002). Kinerja Organisasi diukur dengan 20 item yang terdiri dari 5 item untuk perspektif keuangan, diadaptasi dari Malbasic \& Marimon (2019), 5 item untuk perspektif pelanggan, diadaptasi dari Malbasic \& Marimon (2019), 5 item untuk perspektif proses internal, diadaptasi dari Malbasic \& Marimon (2019), dan 5 item untuk perspektif pertumbuhan yang 
diadaptasi dari Malbasic \& Marimon, (2019). Responden diminta untuk menyatakan setuju dengan item yang ditanyakan dengan pilihan antara 1 (sangat tidak setuju) sampai 10 (sangat setuju).

Data yang terkumpul dianalisis dalam dua tahap. Tahap pertama adalah analisis deskriptif. Analisis ini bertujuan untuk mendeskripsikan variabel yang diteliti. Tahap kedua adalah analisis verifikasi. Analisis ini bertujuan untuk memverifikasi hipotesis yang diajukan. Analisis SEM dengan pendekatan PLS digunakan dalam analisis ini. Ada tiga tahapan analisis dalam analisis PLS-SEM. Pertama, analisis model pengukuran, kemudian dilanjutkan dengan analisis model struktural. Terakhir, pengujian hipotesis (Hair et al., 2017).

\section{Hasil}

Responden terbagi dalam dua kelompok, yaitu kelompok pengusaha dan kelompok pengrajin. Kelompok pengusaha terdiri dari 40 orang (lebih besar dari ketentuan minimal 25 orang) sedangkan kelompok pengrajin 260 orang. Jadi, total ada 300 responden. Mayoritas responden yaitu $77 \%$ adalah perempuan. Angka ini menegaskan bahwa industri batik Jambi adalah domain perempuan. Hal ini dapat dimaklumi karena industri batik Jambi berawal dari industri rumah tangga yang di dalamnya perempuan berperan besar. Namun, pada kelompok pengusaha, jumlah laki-laki relatif banyak, yaitu 40\% dari total jumlah pengusaha. Hal ini mungkin dikarenakan industri batik Jambi yang semakin berkembang sehingga dapat dijadikan sebagai sumber pendapatan utama bagi keluarga. Segi usia, 78\% responden didominasi oleh mereka yang berusia 35 tahun ke atas. Data ini menunjukkan bahwa angkatan kerja yang lebih muda tidak memandang industri batik Jambi sebagai pekerjaan yang menghasilkan pendapatan yang menjanjikan. Dalam hal masa kerja, responden didominasi oleh mereka yang telah bekerja selama sepuluh tahun ke atas. Hal ini menegaskan kurangnya minat generasi muda untuk berkarir di industri batik Jambi. Dari segi pendidikan formal, responden baik pada kelompok pengusaha maupun pengrajin didominasi oleh mereka yang berpendidikan SLTA ke bawah. Data ini dapat menunjukkan bahwa sumber daya manusia merupakan salah satu tantangan yang harus dihadapi dalam pengembangan industri batik Jambi.

Tabel 1 merangkum deskripsi variabel penelitian. Tabel ini menunjukkan bahwa praktek rekrutmen, pelatihan, dan penilaian kinerja belum dilaksanakan secara efektif. Akibatnya, penerapan praktek MSDM secara keseluruhan juga dinilai kurang efektif. Menariknya, praktek kompensasi dinilai cukup baik. Artinya responden dianggap cukup puas dengan sistem kompensasi yang diterapkan. HC merupakan aspek yang sangat penting untuk mencapai kinerja. Di industri batik Jambi, secara keseluruhan HC dinilai cukup baik. Hal ini terlihat dari ketiga dimensi yang diukur menunjukkan nilai yang cukup baik. Artinya perajin dianggap memiliki kompetensi, sikap, dan kelincahan yang memadai. Kinerja tugas perajin dinilai cukup tinggi. Demikian pula kinerja kontekstual dan kinerja adaptif dinilai cukup baik. Artinya kinerja perajin secara umum dinilai baik. Data ini dapat menunjukkan bahwa perajin memiliki kinerja yang baik meskipun belum maksimal. Dari keempat dimensi kinerja organisasi terlihat bahwa kinerja keuangan, pelanggan, dan proses internal dinilai cukup bagus. Namun, kinerja pertumbuhannya dinilai kurang baik. Hal ini membuat kinerja organisasi secara keseluruhan hanya pada tingkat yang moderat.

\section{Tabel 1}

\section{Deskripsi Variabel}

\begin{tabular}{|c|c|c|c|}
\hline Variablel & Dimensi & Index $(\%)$ & Category \\
\hline \multirow{5}{*}{ Praktek MSDM } & Rekrutmen \& Seleksi & 61 & Rendah \\
\hline & Pelatihan \& Pengembangan & 62 & Rendah \\
\hline & Kompensasi & 66 & Sedang \\
\hline & Penilaian kinerja & 61 & Rendah \\
\hline & Rata-rata & 61 & Sedang \\
\hline \multirow{4}{*}{ Human Capial } & Kompetensi & 64 & Sedang \\
\hline & Sikap & 65 & Sedang \\
\hline & Agilitas Intelektual & 65 & Sedang \\
\hline & Rata-rata & 65 & Sedang \\
\hline \multirow{4}{*}{ Kinerja Individu } & Kinerja Tugas & 65 & Sedang \\
\hline & Kinerja Kontekstual & 65 & Sedang \\
\hline & Kinerja Adaptif & 65 & Sedang \\
\hline & Rata-rata & 65 & Sedang \\
\hline \multirow{5}{*}{ Kinerja Organisasi } & Perspektif keuangan & 69 & Sedang \\
\hline & Perspektif pelanggan & 65 & Sedang \\
\hline & Perspektif proses internal & 65 & Sedang \\
\hline & Perspektif pertumbuhan & 63 & Sedang \\
\hline & Rata-rata & 65 & Sedang \\
\hline
\end{tabular}

Sumber: data olahan 
Tabel 2

The loading factor

\begin{tabular}{|c|c|c|c|c|c|c|c|}
\hline Praktek MSDM & & Human Capital & & Kinerja Individu & & Kinerja Organisasi & \\
\hline $\mathrm{X} 11$ & 0,811 & M111 & 0,864 & M211 & 0,864 & Y11 & 0,822 \\
\hline $\mathrm{X} 12$ & 0,803 & M112 & 0,872 & M212 & 0,860 & Y12 & 0,824 \\
\hline $\mathrm{X} 13$ & 0,802 & M113 & 0,892 & M213 & 0,902 & Y13 & 0,831 \\
\hline $\mathrm{X} 14$ & 0,842 & M121 & 0,931 & M214 & 0,931 & Y14 & 0,884 \\
\hline $\mathrm{X} 15$ & 0,846 & M122 & 0,898 & M215 & 0,892 & Y15 & 0,887 \\
\hline $\mathrm{X} 21$ & 0,797 & M123 & 0,923 & M221 & 0,913 & Y21 & 0,843 \\
\hline $\mathrm{X} 22$ & 0,840 & M131 & 0,926 & M222 & 0,911 & Y22 & 0,852 \\
\hline $\mathrm{X} 23$ & 0,843 & M132 & 0,929 & M223 & 0,862 & Y23 & 0,864 \\
\hline $\mathrm{X} 24$ & 0,858 & M133 & 0,929 & M224 & 0,861 & Y24 & 0,857 \\
\hline $\mathrm{X} 25$ & 0,859 & & & M225 & 0,893 & Y25 & 0,854 \\
\hline X31 & 0,821 & & & M226 & 0,930 & Y31 & 0,834 \\
\hline X32 & 0,855 & & & M231 & 0,892 & Y32 & 0,876 \\
\hline X33 & 0,835 & & & M232 & 0,903 & Y33 & 0,864 \\
\hline X34 & 0,787 & & & M233 & 0,913 & Y34 & 0,849 \\
\hline X35 & 0,834 & & & M234 & 0,907 & Y35 & 0,866 \\
\hline X41 & 0,812 & & & M235 & 0,910 & Y41 & 0,853 \\
\hline X42 & 0,803 & & & & & Y42 & 0,847 \\
\hline X43 & 0,818 & & & & & Y43 & 0,869 \\
\hline X44 & 0,837 & & & & & Y44 & 0,771 \\
\hline X45 & 0,864 & & & & & Y45 & 0,757 \\
\hline
\end{tabular}

Sumber: data olahan

Tabel 2 hasil pengolahan data dari 300 responden menunjukkan bahwa nilai loading factor masing-masing item lebih besar dari 0,7 dan nilai Average Variance Extracted (AVE) lebih besar dari 0,5 (Tabel 3). Hasil ini menunjukkan bahwa semua indikator dianggap valid secara konvergen untuk mengukur konstruk. Hasil pengolahan data juga menunjukkan bahwa indikator memenuhi kriteria Fornell-Larcker (Tabel 4) dan nilai cross-loading lebih besar dari 0,5. Hal ini menunjukkan bahwa semua indikator memenuhi validitas diskriminan yang berarti bahwa setiap indikator merupakan ukuran konstruk yang unik.

Tabel 3

Average Variance Extracted (AVE)

\begin{tabular}{lc}
\hline & Average Variance Extracted $(A V E)$ \\
\hline Human Capital & 0,824 \\
Kinerja Individu & 0,804 \\
Kinerja Organisasi & 0,715 \\
Praktek MSDM & 0,687 \\
\hline
\end{tabular}

Sumber: data olahan

Tabel 4

The Fornell-Larcker Criterion

\begin{tabular}{lrrrr}
\hline & Praktek MSDM & HC & Kinerja Individu & Kinerja Organisasi \\
\hline Praktek MSDM & 0,829 & 0,793 & 0,819 & 0,292 \\
Human Capital & & 0,908 & 0,897 & 0,266 \\
Kinerja Individu & & & & 0,326 \\
Kinerja Organisasi & & & 0,846 \\
\hline Sumber:
\end{tabular}

Sumber: data olahan

Reliabilitas diartikan sebagai konsistensi jawaban responden. Dalam PLS-SEM, reliabilitas dilihat dari dua kriteria, yaitu nilai Cronbach's Alpha, dan reliabilitas komposit. Indikator suatu konstruk dikatakan reliabel jika nilai Cronbach's Alpha $>0.6$ dan nilai composite reliability $>0.8$. Hasil pengolahan data menunjukkan bahwa nilai Cronbach's Alpha $>0,7$ dan nilai composite reliability $>0,8$ (Tabel 5), sehingga dapat disimpulkan bahwa indikator yang digunakan untuk mengukur konstruk laten memiliki reliabilitas. Dengan demikian dapat dilakukan analisis selanjutnya yaitu analisis model struktural. 
Tabel 5

The value of Cronbach's Alpha and Composite Reliability

\begin{tabular}{lrr}
\hline & Cronbach's Alpha (>0,6) & Composite Reliability (>0,8) \\
\hline Human Capital & 0,973 & 0,977 \\
Kinrja Individu & 0,984 & 0,985 \\
Kinerja Organisasi & 0,979 & 0,980 \\
Praktek MSDM & 0,976 & 0,978 \\
\hline
\end{tabular}

Sumber: data olahan

Analisis model struktural dilakukan untuk memastikan bahwa model yang dibangun kuat atau akurat. Akurasi ini dilihat dari hasil koefisien determinasi (R2), predictive relevansi (Q2), effect size (f2), dan Goodness of Fit (GoF). Koefisien determinasi (R2) menunjukkan seberapa besar pengaruh eksogen terhadap endogen. Hasil analisis (Tabel 6) menunjukkan bahwa nilai R2 untuk HC adalah 0,629 yang berarti 63\% dari HC dapat dijelaskan oleh praktek MSDM. Sedangkan nilai R2 kinerja individu sebesar 0,671 yang berarti 67\% kinerja individu dapat dijelaskan oleh praktek MSDM. Sedangkan nilai R2 kinerja organisasi adalah 0,701, yang berarti 70\% kinerja organisasi dapat dijelaskan oleh praktek MSDM, HC, dan kinerja individu. Dari hasil pengolahan ini juga terlihat bahwa praktek MSDM dapat meningkat jika dimediasi oleh $\mathrm{HC}$ dan kinerja individu. Hasil koefisien determinasi diperkuat dengan analisis prediktif relevansi. Pengolahan data secara manual dengan rumus Q2 $=1-(1-0,629)(1-0,671)(1-0,702)=1-0,036374=$ $0,963626=0,96$ menghasilkan nilai Q2 $=0,96$ yang artinya 96\% kinerja organisasi dijelaskan oleh praktek MSDM, HC, dan kinerja individu. Namun, nilai f2 diketahui 0,092 untuk hubungan antara praktek MSDM dan kinerja organisasi (Tabel 7). Ini berarti bahwa pengaruh praktek MSDM terhadap kinerja organisasi adalah lemah. Hasil pengolahan data ini menunjukkan bahwa praktek MSDM memiliki pengaruh besar pada kinerja organisasi ketika dimediasi oleh $\mathrm{HC}$ dan kinerja individu.

Tabel 6

R-Square

Human Capital

R Square

Kinerja Individu

0,629

Kinerja Organisasi

0,671

Sumber: data olahan

Tabel 7

Effect Size $\left(\mathbf{f}^{2}\right)$

Human Capital Kinerja individu Kinerja Organisasi

\begin{tabular}{lrr} 
& & \\
Human Capital & & 0,032 \\
Kinerja Individu & & 0,042 \\
Kinerja Organisasi & 1,695 & 0,092 \\
\hline
\end{tabular}

Sumber: data olahan

Bagian terakhir dari evaluasi model struktural adalah model fit test. Model jalur yang diusulkan dinilai sangat 'robust' jika nilai Goodness of Fit (GoF) adalah 0,38. Perhitungan manual GoF dilakukan dengan rumus (AVE x $\mathrm{R}^{2}$ ). Hasilnya nilai GoF berada di atas 0,38 . Dengan demikian, berdasarkan hasil analisis GoF ditambah nilai $\mathrm{R}^{2}, \mathrm{f}^{2}$, dan $\mathrm{Q}^{2}$, disimpulkan bahwa model struktur yang diajukan adalah robust, sehingga pengujian hipotesis. Hasil uji hipotesis menunjukkan bahwa semua hipotesis yang diajukan dapat diterima. Hal ini terlihat dari nilai P semua variabel kurang dari 0,05. Dengan kata lain, praktek MSDM berpengaruh positif dan signifikan terhadap HC (H1), kinerja individu (H2), dan kinerja organisasi (H3). Kemudian, HC berpengaruh positif dan signifikan terhadap kinerja organisasi (H4). Demikian juga kinerja individu berpengaruh positif dan signifikan terhadap kinerja organisasi (H5).

Hasil uji mediasi menunjukkan bahwa nilai t-statistik lebih signifikan dari 1,96 dan nilai signifikansi lebih signifikan dari 0,05 yang berarti bahwa hubungan antar variabel dalam model signifikan. Hal ini menunjukkan bahwa HC memediasi praktek MSDM pada kinerja organisasi (H6) dan kinerja individu memediasi dampak praktek MSDM terhadap kinerja organisasi (H7). Analisis deskriptif menunjukkan bahwa praktek MSDM di industri batik Jambi belum efektif diterapkan. Hal ini berdampak pada nilai $\mathrm{HC}$ dan nilai kinerja individu. Pada akhirnya berdampak pada kinerja organisasi. Temuan ini diperkuat dengan pengujian hipotesis, yang membuktikan bahwa praktek MSDM berpengaruh signifikan terhadap HC, kinerja individu, dan kinerja organisasi. Analisis koefisien determinasi menjelaskan bahwa praktek MSDM berpengaruh sedang terhadap kinerja organisasi. Namun, pengaruh ini dapat meningkat jika dimediasi oleh $\mathrm{HC}$ atau kinerja individu. Hal ini diperkuat dengan uji mediasi, yang mengungkapkan 
bahwa praktek MSDM memiliki pengaruh tidak langsung yang signifikan terhadap kinerja organisasi melalui $\mathrm{HC}$ atau kinerja individu.

\section{Simpulan}

Tujuan utama dari penelitian ini adalah untuk membuktikan peran mediasi HC dan kinerja individu dalam hubungan antara praktek MSDM dan kinerja organisasi. Hasil pengolahan data pada 300 responden telah mengkonfirmasi hipotesis bahwa praktek MSDM berpengaruh positif dan signifikan terhadap kinerja organisasi melalui HC dan kinerja individu. Sejauh ini, dalam literatur dan hasil penelitian empiris, terungkap bahwa hubungan antara praktek MSDM dan kinerja organisasi tidak jelas dan tidak konsisten. Hasil penelitian saat ini dapat menjadi hal baru dalam organisasi kecil di mana terbukti bahwa HC dan kinerja organisasi dapat memediasi hubungan antara praktek MSDM dan kinerja organisasi. Temuan empiris dalam penelitian ini juga menjelaskan bagaimana praktek MSDM mempengaruhi kinerja organisasi.

\section{Reference}

Al-Tit, A. (2017). Factors affecting the organizational performance of manufacturing firms. International Journal of Engineering Business Management, 9, 1-9. https://doi.org/10.1177/1847979017712628

Allworth, E., \& Hesketh, B. (1999). Construct-oriented Biodata: Capturing Change-related and Contextually Relevant Future Performance. International Journal of Selection and Assessment, 7(2), 97-111. https://doi.org/10.1111/1468-2389.00110

Armstrong, M. (1999). Human Resource Management Practice (3rd ed.). Kogan Page.

Armstrong, M. (2012). Armstrong's Handbook of Human Resource Management Practice. Kogan Page. http://books.google.com/books?id=TCwoAwAAQBAJ\&pgis=1

Armstrong, M., \& Taylor, S. (2014). Armstrong's Handbook of Human Resource Management Practice (13th ed., Vol. 13, Issue 1). Kogan Page Limited. https://doi.org/10.1177/030913258901300105

Babbie, E. (2014). The Basics of Social Research (6th ed.). Wadsworth, Cengange Learning.

Banerjee, R. (2017). A Study of Linkages between Human Resource Management Practices and SMEs Performance in Vadodara District. A Dissertation. Gujarat Technological University.

Barney, J., \& Arikan, A. M. (2008). The Resource-based View: Origins and Implications. The Blackwell Handbook of Strategic Management, 123-182. https://doi.org/10.1111/b.9780631218616.2006.00006.x

Baron, R. M., \& Kenny, D. A. (1986). The Moderator-Mediator Variable Distinction in Social Psychological Research: Conceptual, Strategic, and Statistical Consideration. Journal of Personality and Social Psychology, 51(6), 1173-1182. https://doi.org/10.1007/BF02512353

Becker, G. S. (1964). Human Capital. Columbia University Press.

Borman, W. C., \& Motowidlo, S. J. (1993). Expanding the criterion domain to include elements of contextual performance. In N. Schmitt \& W. C. Borman (Eds.), Personnel Selection in Organizations (pp. 79-98). Jossey-Bass.

BPS Provinsi Jambi. (2020a). Produk Domestik Regional Bruto Provinsi Jambi menurut Lapangan Usaha 2015 2019. BPS Provinsi Jambi.

BPS Provinsi Jambi. (2020b). Survei Angkatan Kerja Nasional (SAKERNAS) Provinsi Jambi Februari 2020.

BPS Provinsi Jambi. (2021). Provinsi Jambi dalam Angka 2021.

Bryson, A., \& Forth, J. (2018). The Impact of Management Practices on SME Performance. National Institute of Economic and Social Research, 488. www.iza.org

Colquitt, J. A., Lepine, J. A., \& Wesson, M. J. (2015). Organizational Behavior: Improving Performance and Commitment in the Workplace (4th ed.). McGraw Hill Education.

Daft, R. L. (2000). Organization Theory and Design (7th ed.). South-Western College Publishing. Thomson Learning.

Gamage, A. S. (2014). Recruitment and Selection Practices in Manufacturing SMEs in Japan: An analysis of the link with business performance. Ruhuna Journal of Management and Finance, 1(1), 37-52. https://doi.org/10.4038/suslj.v13i1.7668

Gamage, A. S., \& Sadoi, Y. (2008). Determinants of Training and Development Practices in SMEs: A Case of Japanese Manufacturing Firms. Sri Lankan Journal of Human Resource Management, 2(1), 46-61. https://doi.org/10.4038/sljhrm.v2i1.5104

Guest, D. E. (2011). Human resource management and performance: Still searching for some answers. Human Resource Management Journal, 21(1), 3-13. https://doi.org/10.1111/j.1748-8583.2010.00164.x

Hair, J. F., Hult, G. T. M., Ringle, C. M., \& Sarstedt, M. (2017). A Primer on Partial Least Squares Structural Equation Modeling (PLS-SEM). In Sage. SAGE Publications, Inc.

Huselid, M. A. (1995). The Impact of Human Resource Management Practices on Turnover, Productivity, and Corporate Financial Performance. Academy of Management Journal, 38(3), 635-672. 
https://doi.org/10.2307/256741

Kaplan, R. S., \& Norton, D. P. (1992a). The Balanced-Scorecard - Measures that Drive Performance. Harvard Business Review, 1, 71-79.

Kaplan, R. S., \& Norton, D. P. (1992b). The Balanced Scorecard: Measures That Drive Performance. Harvard Busines Review.

Keegan, D. P., Eiler, R. P., \& Jones, C. R. (1989). Are your performance measures obsolete? Strategic Finance, $70(12), 45$.

Khan, N. R., \& Khan, M. R. (2012). Human Resource Practices in SME Sector: An Exploratory Case Study of Pakistan. Euro Economica, 3(31), 7-19.

Koopmans, L., Bernaards, C. M., Hildebrandt, V. H., Schaufeli, W. B., De Vet Henrica, C. W., \& Van Der Beek, A. J. (2011). Conceptual frameworks of individual work performance: A systematic review. Journal of Occupational and Environmental Medicine (JOEM), $53(8), \quad 856-866$. https://doi.org/10.1097/JOM.0b013e318226a763

Malbasic, I., \& Marimon, F. (2019). A Simplified Balanced 'Balanced Scorecard.' European Accounting and Management Review, 5(2), 38-60. https://doi.org/10.26595/eamr.2014.5.2.3

Mangai, R. A. (2011). A Study on Human Resource Practices in Small and Medium Enterprises in Chennai. A Dissertation. Mother Theresa Women's University.

Obeidat, B. Y., Tarhini, A., Masadeh, R., \& Aqqad, N. O. (2017). The impact of intellectual capital on innovation via the mediating role of knowledge management: A structural equation modelling approach. International Journal of Knowledge Management Studies, 8(3-4), 273-298. https://doi.org/10.1504/IJKMS.2017.087071

Octavia, A., \& Sriayudha, Y. (2017). Lingkungan Bisnis dan Kinerja UKM Batik Jambi. Prosiding Seminar Nasional AIMI, 276-282.

Pulakos, E. D., Schmitt, N., Dorsey, D. W., Arad, S., Hedge, J. W., \& Borman, W. C. (2002). Predicting adaptive performance: Further tests of a model of adaptability. Human Performance, 15(4), 299-323. https://doi.org/10.1207/S15327043HUP1504_01

Sabiu, M. S., Ringim, K. J., Mei, T. S., \& Joarder, M. H. R. (2019). Relationship between human resource management practices, ethical climates and organizational performance, the missing link. PSU Research Review, 3(1), 50-69. https://doi.org/10.1108/prr-12-2016-0022

Schultz, T. W. (1961). Investment in human capital. The American Economic Review, 51(1), 1-17.

Siregar, A. P., Raya, A. B., Nugroho, A. D., Indana, F., Prasada, I. M. Y., Andiani, R., Simbolon, T. G. Y., \& Kinasih, A. T. (2020). Upaya pengembangan industri batik di Indonesia. Dinamika Kerajinan Dan Batik (DKB): Majalah Ilmiah, 37(1), 79-92. https://doi.org/10.22322/dkb.V36i1.4149

Snell, S. A., \& Dean, J. W. (1992). Integrated Manufacturing and Human Resource Management: A Human Capital Perspective. Academy of Management Journal, 35(3), 467-504. https://doi.org/10.5465/256484

Tovstiga, G., \& Tulugurova, E. (2007). Intellectual capital practices and performance in Russian enterprises. Journal of Intellectual Capital, 8(4), 695-707.

ul Rehman, W., Rehman, C. A., \& Ilyas, M. (2015). Linking Intellectual Capital and Knowledge Management with Organizational Performance: A Meta-Review Analysis. Kuwait Chapter of Arabian Journal of Business and Management Review, 5(2), 63-73.

Yang, C.-C., \& Lin, C. Y.-Y. (2009). Does intellectual capital mediate the relationship between HRM and organizational performance? Perspective of a healthcare industry in Taiwan. The International Journal of Human Resource Management, 20(9), 1965-1984. 